\title{
INDICADORES SOCIAIS HABITACIONAIS: UMA REFLEXÃO TEÓRICA SOBRE O CÁLCULO DO DÉFICIT HABITACIONAL
}

\author{
Gustavo Henrique Petean ${ }^{1}$, Leandro Sauer ${ }^{2}$ \\ ${ }^{1}$ Universidade Federal de Goiás - UFG. ${ }^{2}$ Universidade Federal de Mato Grosso do Sul - UFM. E-mail: \\ gustah@gmail.com
}

\section{RESUMO}

O cálculo nacional do déficit habitacional 'oficial' é realizado pela Fundação João Pinheiro - FJP, a partir dos dados coletados pelo IBGE. Se utilizam de dois subitens um quanto ao déficit habitacional, por incremento de estoque e por reposição de estoque, e outro por inadequação dos domicílios. Os domicílios em déficit, são aqueles que necessitam da construção de uma nova residência, no item incremento, mensura os domicílios improvisados, em coabitação e com ônus excessivo de aluguel; o item reposição de estoque refere-se aos domicílios rústicos e com depreciação superior a 50 anos. Já os domicílios que apresentam alguma inconformidade são contabilizados no subitem inadequação de domicílios. O objetivo deste trabalho é realizar uma discussão teórica acerca do tema de indicadores sociais e o déficit habitacional, apontando questões de conceito e da metodologia nacionalmente aceita de cálculo do déficit habitacional. Este ensaio teórico utiliza-se da pesquisa bibliográfica e análise documental das publicações da FJP. Os resultados de pesquisa evidenciam que apesar de amplamente aceita a metodologia possui carências de aplicabilidade, tais como a ausência da idade média dos domicílios e a periodicidade do cálculo. Desta forma, sugere-se alternativas de mensuração do déficit habitacional, com a possibilidade de inclusão de variáveis não consideradas pelas FJP.

Palavras-chave: Programa Minha Casa Minha Vida (PMCMV), Mensuração, Fundação João Pinheiro - FJP.

\section{SOCIAL HABITATIONS INDICATORS: A THEORETICAL REFLECTION ON THE DEFICIT CALCULATION OF HABITATIONS}

\begin{abstract}
The national calculation of the 'official' habitations deficit is carried out by Fundação João Pinheiro - FJP, based on data collected by IBGE. Two subsections are used: one for the habitations deficit, for inventory increase and inventory replacement, and the other for inadequacy of households. Households in deficit are those that need the construction of a new residence, in the item increment, measure the improvised households, in cohabitation and with excessive rent burden; the stock replacement item refers to rustic households with depreciation over 50 years. On the other hand, the households that present some nonconformity are counted in the subsection inadequacy of households. The objective of this work is to conduct a theoretical discussion about the theme of social indicators and the housing deficit, pointing out questions of concept and the nationally accepted methodology of calculating the habitations deficit. This theoretical essay uses bibliographic research and documentary analysis of FJP publications. The research results show that although the methodology is widely accepted, it lacks applicability, such as the absence of the average age of the households and the periodicity of the calculation. Therefore, we suggest alternatives to measure the habitations deficit, with the possibility of inclusion of variables not considered by the FJP.

Keywords: Programa Minha Casa Minha Vida (PMCMV); Measurement, Social Indicators, Fundação João Pinheiro - FJP.
\end{abstract}

\section{INTRODUÇÃO}

A casa própria é para a grande maioria da população brasileira uma conquista recente e para tantos outros continua sendo um sonho. $O$ problema habitacional brasileiro tem como marco da gênese a vinda da corte e da família 
real portuguesa para o Brasil (PENALVA e DUARTE, 2011), agravado pela abolição da escravatura, (MARICATO, 2001), contudo, incomparáveis com os números do século XX. O início das atividades industriais brasileiras trouxe para os centros urbanos inúmeros camponeses em busca de oportunidades. Com o passar das décadas, o déficit habitacional é intensificado, e na década de 1960 o governo militar instala a primeira grande política habitacional brasileira, com a aprovação da lei no 4.380/64, marcando a formação do BNH (Banco Nacional de Habitação) e do SFH (Sistema Financeiro de Habitação). Com origem controvérsia, há afirmações que $\mathrm{O}$ BNH surgiu para despertar o espírito individualista e conservador da população brasileira (BONDUKI, 2009).

Operante por vários anos o $\mathrm{BNH}$, ficou ativo até o final da década de 1980 , quando foi dissolvido e a responsabilidade pelo crédito de incentivo habitacional foi transferido para a Caixa Econômica Federal. Entretanto, os anos que sucederam, foram anos de crises financeiras e influência do estado neoliberal (VALENÇA, 2001). Nenhuma medida concreta e significativa de política pública para o setor ocorreu neste período, apenas tramitações de algumas leis, como o estatuto das cidades e pouca articulação entre as esferas federais, estaduais e municipais (HOLANDA, 2010).

Este cenário é modificado após a instituição do programa minha casa minha vida (PMCMV), com a proposta de construção de um milhão de residências (BONDUKI, 2019). Houve alteração no cenário a partir do ano de 2010, contudo, ainda não ser mensurado tal avanço, pois somente no próximo Censo de 2020 que terse-á um novo panorama nacional para o déficit. Muito se aponta para os impactos econômicos do PMCMV (GONÇALVES JÚNIOR et al., 2014) contudo, os impactos precisos referente a atualização do déficit habitacional ainda não é possível.

O breve histórico da evolução do déficit habitacional apresentado acima, faz-se paralelo com o desenvolvimento dos indicadores sociais. As primeiras contribuições para construção de um marco conceitual sobre Indicadores Sociais se dá no início do século XX, nas décadas de 1920 e 1930, porém o grande desenvolvimento da área é recente, apenas na década de 1960 adquiriu corpo científico, na tentativa de organização, de acompanhamento, de transformação social e aferição do impacto de políticas públicas na sociedade (JANNUZZI, 2009). Os primeiros indicadores surgiram nos Estados Unidos da América com o objetivo de mensurar taxas sobre a forma de vida dos americanos (BAUER, 1966; KLEIN, 1974).

O período da década de 1960 evidenciou dicotomias entre o crescimento econômico e as melhores condições sociais da população, principalmente nos países de terceiro mundo, ou em desenvolvimento (a nomenclatura atualmente aceita). Mesmo com os resultados crescentes do produto interno bruto (PIB), persistiam os altos níveis de pobreza, acentuando as desigualdades sociais. Tal situação evidenciou que apenas o crescimento econômico não era condição suficiente para garantir desenvolvimento social. Assim, o PIB per capita, utilizado até então como indicador de nível de desenvolvimento social, se mostra impróprio como medida de bem-estar social (SEN, 2010) e monitoramento de mudanças sociais (JANNUZZI, 2002).

Diante da incapacidade de mensuração, empreendeu-se por várias instituições como, Organização para a Cooperação e Desenvolvimento Econômico - OCDE, Organização das Nações Unidas para a Educação, a Ciência e a Cultura - UNESCO, Organização das Nações Unidas para a Alimentação e Agricultura FAO, Organização Internacional do Trabalho OIT, Organização Mundial de Saúde - OMS, Fundo das Nacções Unidas para a Infância - UNICEF e Divisão de Estatística das Nações Unidas - UNSD, um grande esforço para conceituar e criar metodologias visando o desenvolvimento de instrumentos de mensuração de bem-estar e de mudança social (CREASE, 2013). Esperava que os indicadores fossem utilizados para orientar as ações governamentais, redistribuindo renda, superando as iniquidades do desenvolvimento econômico acelerado e proporcionando níveis crescentes de bem-estar social (JANNUZZI, 2009).

Muitos órgãos (universidades, sindicatos, centros e agências de pesquisas) desenvolveram, aprimoram conceitualmente e metodologicamente os vários indicadores, constituindo um rico e diversificado acervo de indicadores sociais (JANNUZZI, 2009). Contudo, tal uso destes instrumentos não se deu de imediato (SLIWIANY, 1987). Entre os exemplos tem-se o IDH (índice de desenvolvimento humano).

No rol de indicadores possíveis para a contabilidade do déficit habitacional há uma 
divisão metodológica deste cálculo, sendo o déficit habitacional a soma do número de residências deficitárias em reposição de estoque e, as residências necessárias com base no incremento de estoque e/ou inadequação de domicílios. Tal divisão é didática ao idealizar e propor medidas que busquem o fim do déficit habitacional, atualmente no Brasil, o cálculo do déficit habitacional é realizado preferencialmente pela Fundação João Pinheiro - FJP.

Este ensaio apresenta uma discussão teórica dos indicadores sociais, sua definição, seus sistemas, e propriedades desejáveis, correlacionando-os com o cálculo do déficit habitacional e da metodologia empregada pela FJP. Pautado em tais discussões o ensaio dividese em quatro partes. Apresentado a introdução, tem-se a metodologia que elucida sobre as técnicas utilizadas no ensaio. Na sequência na discussão, há uma divisão em dois subitens, no primeiro, traz conceitos prévios de indicador social a partir de uma revisão teórica sobre o tema e em, do item dois, discute a perspectiva de déficit habitacional com luz na metodologia da FJP, apresentando seus aspectos principais e por fim, as considerações finais.

\section{MÉTODOS}

Este artigo é um ensaio teórico que tem como objetivo o resgate e apresentação de conceitos sobre indicadores sociais e déficit habitacional. Baseado em pesquisa bibliográfica, tem-se como referência os principais autores da área com base em números de citações na base Scielo e Google Acadêmico, apresenta e discute a metodologia proposta pela FJP apresentando possibilidades de aprimoramento desta metodologia.

\section{DISCUSSÃO}

\subsection{Indicadores Sociais}

Para Fonte (2004, pág. 3) "os indicadores podem enriquecer a interpretação empírica da realidade social e orientar de forma mais competente a análise, formulação e implementação das políticas públicas". Nesta perspectiva é apresentado o conceito de indicador: "uma medida em geral quantitativa dotada de significado social substantivo, usado para substituir, quantificar ou operacionalizar um conceito social abstrato, de interesse teórico ou programático" (JANNUZZI, 2009, pág. 15). O autor prossegue informando que "é um recurso metodológico, empiricamente referido, que informa algo sobre um aspecto da realidade social ou sobre mudanças que estão se processando na mesma" (pág. 15). Outro conceito utilizado é de Kayano e Caldas (2002, pág. 2), os indicadores enquanto "instrumentos importantes para controle gestão e verificação e medição de eficiência e eficácia (...) principalmente na administração pública, por permitirem comparar situações entre localidades".

$O$ indicador social, para a pesquisa acadêmica, liga o modelo explicativo da teoria social e a evidência empírica dos fenômenos sociais observados (FONTE, 2004). Já na perspectiva programática ele é um instrumento operacional utilizado no monitoramento da realidade social, respalda assim, a formulação, reformulação e acompanhamento de políticas públicas. Os indicadores sociais traduzem de forma compreensiva e passível de comparação diversas dimensões relevantes, específicas e dinâmicas da realidade social (JANNUZZI, 2009; DRUCK, 2011). Estes indicadores passam por um processo de agregação de valor informacional até serem lapidados em indicador. Primeiro se tem os eventos, posteriormente os dados brutos e, por fim, as informações sintetizadas para análise e decisão (CARVALHO e BARCELLOS, 2009). Estas informações podem ser um único indicador ou um grupo, ou sistema de indicadores.

Pode-se conceituar um sistema de indicadores sociais como "um conjunto de indicadores referidos a um determinado aspecto da realidade social ou área de intervenção programática" (JANNUZZI, 2009, pág. 17). Januzzi (2009) ainda retrata a semelhança do sistema ao espaço geométrico euclidiano, fazendo-se necessário um sistema de coordenadas para definir um ponto, o espaço social exige um sistema de indicadores para caracterizar um fenômeno social. O sistema de indicadores sociais contempla os usuários com informações completas e diferenciadas, facilitando a leitura e interpretação desses dados, e expressando com veemência os aspectos sociais de uma determinada comunidade (BIDERMAN, 1966).

A quantidade de informações utilizadas na definição do indicador, ou complexidade metodológica, é um critério de diferenciação de dois conjuntos de indicadores: simples ou compostos. Os indicadores simples são construídos a partir de uma estatística social específica, de elaboração pouco complexa. Já os 
indicadores compostos, ou sintéticos, são obtidos mediante a síntese de dois ou mais indicadores simples (SCANDAR NETO, JANUZZI e SILVA, 2008). $\mathrm{O}$ IDH - Índice de Desenvolvimento Humano - é um exemplo de indicador sintético, formado pela combinação de indicadores simples de saúde, educação e renda. Idealizado pelo economista indiano Amartya Sen, reúne alguns indicadores simples, e mensuro em uma escala de 0 a 1 , 0 índice de desenvolvimento humano. Nesta escala, o um, representa um excelente desenvolvimento humano, e zero nenhum desenvolvimento. Tal índice representa a sintetização de todo um movimento em busca de uma medida satisfatória para mensurar bemestar social em contraste à taxa PIB per capita (SAUER, 2003).

A justificativa para construção de indicadores compostos é a simplicidade e capacidade de síntese dos mesmos, permitindo a orientação objetiva dos tomadores de decisão das políticas públicas, diferentemente dos sistemas de indicadores (SCANDAR NETO, JANUZZI e SILVA, 2008). Entretanto, esta síntese pode incorrer na perda de proximidade entre o conceito e a medida e, às vezes, a transparência para os usuários. Neste cuidado, Jannuzzi (2009) apresenta as propriedades desejáveis de um indicador social. São elas: relevância social; validade de constructo; confiabilidade; grau de cobertura; especificidade; sensibilidade; apógrafo; comunicabilidade; periodicidade; custos factíveis; desagregabilidade; e, historicidade.

A relevância social é o atributo que justifica a elaboração de um indicador. Também legitima o seu emprego no processo de análise, formulação e na implementação de políticas públicas. Esta propriedade é de determinação histórica, resultante de discussões de cada sociedade ao longo de sua trajetória. A validade corresponde ao grau de proximidade entre conceito e medida. E a confiabilidade, por sua vez, está relacionada à qualidade do levantamento dos dados utilizados, podendo ser comparado a uma balança, quando confiável sempre acusa mesma medida, o indicador confiável sempre exibirá a mesma cifra (JANNUZZI, 2009).

O grau de cobertura indica a amplitude geográfica. A depender da finalidade de uso do indicador, tal atributo é essencial, em indicadores amplos, derivados de pesquisa nacional possuem utilidade no planejamento público. Entretanto, os indicadores com pequena cobertura espacial podem ser úteis, apresentando conhecimentos específicos acerca da dinâmica conjuntural da economia e do emprego no âmbito microrregional (CARDOSO, 1999).

A especificidade que é característica de indicadores compostos ou sintéticos retrata as alterações estritamente ligadas às mudanças da dimensão social estudada. Variando conforme o grau de consistência interna (ou grau de associação) existentes entre as estatísticas utilizadas em sua construção. Nem sempre a combinação de vários indicadores em um só traduz fielmente uma medida social de maior validade. Muitas vezes, é preferível um indicador limitado a um indicador com significado abstrato e não específico (JANNUZZI, 2009).

A sensibilidade possui a capacidade de refletir as mudanças, está diretamente ligada à validade e confiabilidade. Um indicador com esta característica possibilita a construção de linhas históricas que acompanham a realidade. O apógrafo ou inteligibilidade corresponde à transparência de sua metodologia, assim os agentes envolvidos, mesmo que não concordem, podem compreender os critérios objetivos utilizados. A comunicabilidade, por sua vez, representa o poder de comunicação do indicador com os agentes. Estes dois pontos, inteligibilidade e comunicabilidade, são essenciais para garantir a transparência e legitimar o uso programático deste indicador (JANNUZZI, 2009).

O conceito de periodicidade representa o poder de comunicação do indicador com os agentes. Estes dois pontos, inteligibilidade e comunicabilidade, são essenciais para garantir a transparência e legitimar o uso programático deste indicador. Os custos factíveis estão ligado diretamente à periodicidade. Pois carece de um custo aceitável para construção e atualização deste indicador.

Por vezes, o valor dispendido é maior na pesquisa para acompanhamento, que o recurso empregado na própria política pública. A desagregabilidade ou a capacidade de divisão de um indicador em vários índices como sócio demográfico, socioeconômico e geograficamente, traduz a necessidade de referência a certos grupos ou locais é o que faz desta uma propriedade desejável. E, por fim, a historicidade que traduz a capacidade de dispor de uma série histórica extensa e comparável é outra desejada propriedade (JANNUZZI, 2009.) 
Apesar de todas as propriedades acima serem desejadas, Jannuzzi (2009 pág. 31) adverte "é muito raro dispor de indicadores sociais que gozem plenamente de todas estas propriedades". E aconselha ao escolher as estatísticas para formar um indicador, verificar a relação recíproca entre conceito e os indicadores propostos. Uma vez que, como adverte Fonte (2004, pág. 4),

"os indicadores sociais foram concebidos para responder a inquietudes muito particulares, definidas como unidimensionais, quando a realidade, a dinâmica social é complexa e requer a integração e medição de sinergias entre os diferentes componentes que atuam na mesma sociedade. Os indicadores não podem ser peças de informações isoladas, sem que correspondam a um conceito".

Tais passagens, supracitadas, justificam a óbvia assertiva 'indicadores sociais apenas indicam' em substituição da operacionalização da medida, esquecendo o seu conceito (FONTE, 2004; JANNUZZI, 2009).

\subsection{Déficit Habitacional}

A metodologia utilizada a nível nacional fora desenvolvida pela Fundação João Pinheiro, que conforme descrição encontrada no sitio eletrônico da fundação, a caracteriza como:

$$
\begin{aligned}
& \text { “Órgão oficial de } \\
& \text { estatística de Minas } \\
& \text { Gerais, a Fundação João } \\
& \text { Pinheiro é uma instituição } \\
& \text { pública vinculada à } \\
& \text { Secretaria de } \\
& \text { Planejamento e } \\
& \text { Atua nas áreas de ensino e } \\
& \text { pesquisa em } \\
& \text { administração pública, } \\
& \text { avaliação de políticas } \\
& \text { públicas e na produção de } \\
& \text { indicadores estatísticos, } \\
& \text { econômicos, demográficos } \\
& \text { e sociais" (FUNDAÇÃO } \\
& \text { JOÃO PINHEIRO, 2011). }
\end{aligned}
$$

Pela experiência adquirida em estudos realizados para o governo mineiro o órgão federal responsável, hoje Ministério das Cidades, incumbiu a FJP do cálculo do déficit habitacional brasileiro, baseado nas pesquisas do Censo e PNAD. O primeiro relatório divulgado pela FJP foi em 1995 referente a pesquisa de 1991, e anualmente divulgam o relatório dos municípios registrados pelo PNAD (FJP, 2005). Apesar de ter construído uma metodologia madura e abrangente, há demora da divulgação dos resultados das pesquisas, fato que prejudica o acompanhamento das políticas públicas. Um exemplo é a divulgação do déficit habitacional baseado no censo 2000 apenas em 2005. O último dado divulgado é do PNAD de 2007, que fora exposto apenas em 2009 (FJP, 2011) e uma prévia com base na PNAD de 2015 somente no ano de 2017 (FJP, 2017).

A metodologia construída pela FJP calcase na busca por entender as necessidades habitacionais brasileiras, assim elaborou uma metodologia de cálculo trabalhando com dois segmentos distintos, o déficit habitacional e a inadequação de moradias.

\subsection{Metodologia da Fundação João Pinheiro}

Como já dito anteriormente o déficit habitacional pode ser entendido como o número de residências que necessitam ser construídas e domicílios inadequados para a utilização. Os domicílios inadequados são conceituados e denominados na metodologia da FJP como déficit por reposição de estoque e/ou por incremento de estoque, como apresentado pela FJP:

"Engloba tanto aquelas moradias sem condições de serem habitadas devido à precariedade das construções ou em virtude de terem sofrido desgaste da estrutura física e que devem ser repostas, quanto à necessidade de incremento do estoque, decorrente da coabitação familiar ou da moradia em locais destinados a fins não residenciais. $O$ déficit habitacional pode ser entendido, portanto, como 'déficit por reposição do estoque' e como 'déficit por incremento de estoque" (FJP, 2005, pág 7). 
Nesta metodologia, o déficit por reposição do estoque engloba os domicílios rústicos, e a parcela devido à depreciação dos imóveis. Classificam-se domicílios rústicos aqueles não possuidores de paredes de alvenaria ou madeira aparelhada. A depreciação dos imóveis considera o tempo máximo de vida útil 50 anos, para imóveis sem obra alguma após a construção. Os déficits por incremento de estoque incluem domicílios improvisados, coabitação familiar, e ônus excessivo com aluguel. É considerado improvisado aquele domicílio alocado em locais não destinados a fins residenciais. A coabitação corresponde a soma de famílias conviventes morando no mesmo domicílio, sendo de famílias secundários (laços consanguíneos de até segundo grau) ou não, juntamente a família principal. Há também os cômodos cedidos ou alugados considerados coabitação disfarçada. O ônus excessivo com aluguel equivale ao gasto superior a $30 \%$ da renda familiar total (FJP, 2005).

Somado ao número por incremento e por reposição, faz-se necessário conhecer as habitações inadequadas que são: habitações que "não proporcionam a seus moradores condições desejáveis de habitabilidade, o que não implica, contudo, necessidade de construção de novas unidades" (FJP, 2005, pág. 8). Os domicílios somados a este quesito são, carentes de infraestrutura, adensamento excessivo de moradores, com problemas de natureza fundiária, com alto grau de depreciação ou sem unidade sanitária domiciliar. "Ao contrário do déficit habitacional, que analisa tanto os domicílios urbanos quanto os rurais, as moradias passíveis de serem identificadas como inadequadas restringem-se às localizadas em áreas urbanas" (FJP, 2005, pág. 24).

A ausência de ao menos um dos serviços básicos, iluminação elétrica, rede geral de abastecimento de água com canalização interna, rede geral de esgotamento sanitário ou fossa séptica e coleta de lixo, é considerado domicílio carente de infraestrutura. $O$ adensamento excessivo ocorre na quantificação de na média igual ou superior a três indivíduos por cômodo, considerando cozinha e banheiro. A inadequação fundiária refere-se ao caso quando os moradores possuem o domicílio mais não possui total ou parcialmente o terreno ou fração ideal do terreno. A parcela de alto grau de depreciação representa a parcela de casas construídas, porém já vem se deteriorando, não chegaram ao máximo de sua vida útil e podem ser adequadas para ganhar sobrevida (FJP, 2005).

Descrito a metodologia da FJP, ao contabilizar estes dados, esta metodologia sofre algumas alterações, como medida de ajustamento ao levantamento de dados já realizado, seja ele o Censo ou a PNAD. Referente a PNAD por não ser executadas em municípios inferiores a 50 mil habitantes o número referente ao déficit é deflacionado ou no máximo estimado. Quando ocorre o Censo, todos os municípios são investigados, mas nem todos os dados são levantados (IBGE, 2010). Ocasionando a necessidade dos devidos ajustes.

O cálculo do déficit habitacional como proposto inicialmente não se pode realizar o cálculo da depreciação dos imóveis e do ônus excessivo com o aluguel, pela ausência de dados. $E$ no item inadequação dos domicílios à depreciação parcial não pode ser calculada (FJP, 2005). Com base no PNAD2008 o cálculo de déficit habitacional ignora o problema da depreciação dos imóveis, retira por completo da sua metodologia e com a seguinte justificativa "em relação aos aspectos metodológicos, tanto as informações levantadas pela PNAD como pelos censos demográficos não permitem o cálculo da depreciação dos imóveis" (FJP, 2011, p. 19).

\section{CONSIDERAÇÕES FINAIS}

Os indicadores em sua base teórica por vezes perdem características empíricas quando calculado, assim os limites e abrangências do indicador proposto neste trabalho baseiam-se nas propriedades desejáveis citadas por Jannuzzi (2009). Estas doze indicações de propriedades desejáveis nortearam a análise do indicador. Uma limitação é quanto à periodicidade do indicador, baseado em uma pesquisa decenal há uma lacuna temporal na atualização do indicador.

Todavia, esta se apresenta com menor gravidade que outras, pois em cidades com maior população o PNAD fornece dados que pode ser utilizado no levantamento do déficit habitacional, e pelo histórico de pesquisa é nos grandes centros que os números relativos ao déficit têm maior impacto. O longo período entre um Censo e outro prejudica o acompanhamento da política pública, entretanto, faz surgir ou deseja-se que surjam outras formas de acompanhamento.

Uma destas formas é a PNAD, que nas cidades onde é realizada utilizam-se com uma maior periodicidade. A pesquisa nacional de amostra de domicílios (PNAD) realizada 
bienalmente revela informações que são úteis em diversas esferas, como exemplo a administração municipal poderia utilizar-se destas informações para o monitoramento ou sugestão de política pública.

Os pequenos municípios que não dispõem dos dados da PNAD enfrentam realidades específicas e necessitam acompanhar o problema de déficit habitacional quase que individualmente, família á família. Ou desenvolver mecanismos de coleta de dados para suprir tais necessidades. Um outro complicador é a série histórica que fica comprometida.

Outro ponto a ser questionado é a dificuldade de replicação do indicador. Para atingir a propriedade desejável de apógrafo, de pode ser repedida por qualquer pessoa com acesso aos dados, os dados da forma que foram desagregados para a FJP deveriam ser divulgados, isto facilitaria a sua disseminação. Esta característica agrega também a comunicabilidade do indicador, mesmo que o indicador se apresenta de fácil compreensão e interpretação, promovendo ao agente público, a facilidade de utilização, seja na implementação, no controle ou na avaliação das políticas públicas.

O IBGE proporciona, pelo método de coleta, a propriedade de amplamente desagregáveis sociodemográfico, socioeconômico e geograficamente. A unidade mínima de divulgação dos dados são os setores, que são agrupados em bairros, em microrregiões, macrorregiões e o município como um todo. Há ainda a possibilidade de desagregação por faixa de renda, e quando verifica-se $o$ déficit habitacional por faixa de renda evidencia que nas classes mais pobres os índices são elevados. Isso ocorre de maneira inversa a renda, pois dificilmente uma pessoa com renda superior enquadra-se nos itens levantados de déficit habitacional e também, possui um acesso facilitado a crédito, entre outros.

Os itens mais complexos dentre as propriedades desejáveis são a especificidade e a sensibilidade do indicador. A tradução de vários índices em apenas um ocorre, por vezes, a perda da identidade e função proposta inicialmente. Como já alertado por JanNuzzi (2009) não se deve perder a proximidade entre o conceito e a medida, tampouco a transparência em detrimento da síntese.

Pelo que realça a metodologia da FJP, buscou-se agrupar de maneira concisa os dados, para que o resultado final do indicador não se perdesse do conceito. A correlação entre as variáveis é que indica a subjetividade do indicador, não bastando apenas agrupar inúmeras variáveis sem preocupar-se com o conceito original do indicador e tão pouco com a relação entre as variáveis.

Já a sensibilidade evidencia-se melhor em formas de comparação, por vezes há uma grande melhoria qualitativa para o bairro não refletida no indicador. Ou inúmeras famílias foram beneficiadas e o indicador pouco melhorou. Há itens mais sensíveis que outros, porém, no conjunto, o indicador da FJP se mostrou sensível as mudanças de realidade. Observa-se isto por testes realizados na construção do indicador ou na comparação utilizando de pesquisas realizadas em anos diferentes que compõe a série histórica do indicador.

Apesar de abordar inúmeras propriedades desejáveis atendidas como nas descritas acima, alguns pontos da metodologia podem ser melhorados, como o aspecto da idade média dos domicílios. Mesmo que não mensurado pelas pesquisas do IBGE poderiam ser utilizadas uma pesquisa amostral ou pela base de índice cadastral do município (base esta utilizada para gerar os valores do IPTU) desde que a mantenham atualizada.

Contudo, este aspecto requer uma atenção subjetiva, pois há cidades de cunho histórico que possuem residências centenárias poderiam mascarar o verdadeiro índice. Neste caso, aplica-se ao cálculo a última reforma estrutural do domicílio. Ao considerar este item no cálculo, deve-se ter o cuidado quanto à subjetividade do tema, as cidades de cunho histórico são particularidades, porém necessitase de atenção no levantamento e disseminação do dado de déficit habitacional.

Outro ponto a ser considerado é o valor estabelecido como teto máximo do aluguel de $30 \%$ da renda bruta. Como já citado anteriormente os problemas habitacionais, em sua maioria, impactam a população de baixa renda, e este valor pré-estabelecido pode incluir ou subtrair famílias em condição de déficit do cálculo real do déficit. Para uma família que enquadrada nos critérios de baixa renda, mesmo que o valor do aluguel não chegue aos $30 \%$ da renda, possui um grande impacto na saúde financeira desta família.

De natureza intrínseca e subjetiva, o déficit habitacional, poderia ser mensurado, por pesquisas independentes, quanto a percepção de 
déficit dos moradores no município. Esta pesquisa poderia ser reveladora, aflorando itens desconsiderados na literatura, como pavimentação asfáltica, contudo, deveria ter-se o cuidado para que não encobrisse itens necessários, porém pouco percebidos pela população, como o esgotamento sanitário. Esta percepção revela valores arraigados na população, valores que influenciam na tomada de decisão dos administradores públicos, e deveriam também ser considerados na construção do déficit habitacional. Possibilitaria a formação de dois índices um quanto à percepção da população e outro, quanto aos itens aqui destacados.

\section{REFERÊNCIAS}

BAUER, R. A. Detections and anticipation of impact: the nature of the task. In: BAUER, R. A. (org.). Social Indicatiors. London: The MIT Press, 1966.

BIDERMAN, A. D. Social indicators and goals. In: BAUER, R. A. (org.). Social Indicatiors. London: The MIT Press, 1966.

BONDUKI, N. Do Projeto Moradia ao programa Minha Casa, Minha Vida. Revista Teoria e Debate, edição 183, abr. 2009. Disponível em: https://teoriaedebate.org.br/2009/05/01/doprojeto-moradia-ao-programa-minha-casaminha-vida/. Acesso em: mar. 2011.

CARDOSO, R. L. S. Elaboração de indicadores de desempenho instituicional e organizacional no setor público: técnicas e ferramentas. São Paulo: fPFL-Cepam, 1999.

CARVALHo, P. G. M. de; BARCELlos, F. C.. Políticas públicas e sustentabilidade ambiental: construindo indicadores de sustentabilidade. Indicadores Econômicos Fee, Porto Alegre, v. 37, n. 1, p.1-14, jan. 2009.

CREASE, R. A Medida do Mundo. Rio de Janeiro: Jorge Zahar, 2013.

DRUCK, G. Trabalho, precarização e resistências: novos e velhos desafios?. Caderno Crh, [s.I.], v. 24, n. 1, p.37-57, 2011.

FONTE, E. M. M. Considerações sobre a importância do conceito de "qualidade de vida" para a construção e uso de indicadores sociais de desenvolvimento na formulação e análise de políticas públicas. In: CONGRESSO LUSO-AFROBRASILEIRO DE CIÊNCIAS SOCIAIS, 8, 2004, Coimbra. Anais [...] Coimbra: Universidade de Coimbra, 2004. p. 1 - 18.

FUNDAÇÃO JOÃO PINHEIRO (FJP). Déficit habitacional no Brasil, 2000. Belo Horizonte: A Fundação. 2005.

FUNDAÇÃO JOÃO PINHEIRO (FJP). Déficit habitacional no Brasil, 2008. Belo Horizonte: A Fundação. 2011.

FUNDAÇÂO JOAO PINHEIRO (FJP) Déficit habitacional no Brasil 2015: resultados preliminares. Belo Horizonte: FJP, 2017.

GONÇALVES JUNIOR, C. A. et al. O impacto do Programa Minha Casa, Minha Vida na economia brasileira: uma análise de insumo-produto. Ambiente Construído, [s.l.], v. 14, n. 1, p.177189, mar. 2014.

HOLANDA, A. C. G. Avanços e Limites da Nova Política de Habitação de Interesse Social. In: SEMINÁRIO NACIONAL GOVERNANÇA URBANA E DESENVOLVIMENTO METROPOLITANO, 01., 2010, Anais [...] Natal: UFRN, 2010. p. 01 - 14.

INSTITUTO BRASILEIRO DE GEOGRAFIA E ESTATÍSICA (IBGE). Censo 2010. Disponível em: http://www.ibge.gov.br/censo2010/. Acesso em: 05 mar. 2011.

JANNUZZI, P. M. Considerações sobre o uso, mau uso e abuso dos indicadores sociais na formulação e avaliação de políticas públicas municipais. RAP: Rio de Janeiro, v.36, n. 1, p.5172, jan./fev. 2002.

JANNUZZI, P. de M. Indicadores sociais no Brasil: conceitos, fontes de dados e aplicações. 4. ed. São Paulo: Alínea, 2009.

KAYANO,J.; CALDAS, E. L. Indicadores para o diálogo. In: SPINK, P; BAVA, S. C; PAULICS, V. Novos contornos da gestão local: conceitos em construção. São Paulo: Pólis, 2002. p. 291-308.

KLEIN, H. A. The science of the measurament: a historical survey. New York: Simon \& Schuster, 1974. 
MARICATO, E. Brasil, Cidades: alternativas para a crise urbana. 2. ed. Petrópolis: Vozes, 2001. 204 p.

PENALVA, A. M. S.; DUARTE, S. M. POLÍTICA HABITACIONAL NO BRASIL: UMA NOVA ABORDAGEM PARA UM VELHO PROBLEMA. RFDRevista da Faculdade de Direito da UERJ, [S.I.], n. 18, abr. 2011. ISSN 2236-3475. Disponível em: <https://www.e-

publicacoes.uerj.br/index.php/rfduerj/article/vie w/1375>. Acesso em: 02 maio 2019. doi:https://doi.org/10.12957/rfd.2010.1375.

SAUER, L. Abordagem bipolar do problema de classificação e escolha. $85 \mathrm{f}$. Tese (Doutorado em Engenharia Elétrica) - Universidade Estadual de Campinas, Campinas, 2003.

SCANDAR NETO, W. J.; JANNUZZI, P. M.; SILVA, P. L. N. Sistemas de Indicadores ou Indicadores Sintéticos: do que precisam os gestores de programas sociais? In: XVI ENCONTRO NACIONAL DE ESTUDOS POPULACIONAIS, 16., 2008, Caxambu. Anais [...] Campinas: Unicamp, 2008. p. 1 - 14.

SEN, A. Desenvolvimento como liberdade. São Paulo: Companhia de Bolso, 2010.

SLIWIANY, R. M. Estatística social: Como medir a qualidade de vida. Curitiba: Araucária cultural, 1987.

VALENÇA, M. M. Globabitação: sistemas habitacionais no Brasil, Grã-Bretanha e Portugal. São Paulo: Terceira Margem, 2001.

Recebido para publicação em 11/11/2017

Revisado em 01/06/2018

Aceito em 10/03/2019 